\title{
Atypical response of class IC atrial flutter to adenosine
}

\section{Risposta atipica alla adenosina di un flutter atriale classe IC}

\author{
Francesco Rotondi, Tonino Lanzillo, Fiore Manganelli, Francesca Lanni, \\ Ferdinando Alfano, Giovanni Stanco, Giuseppe Rosato
}

\begin{abstract}
Atypical response of class IC atrial flutter to adenosine. F. Rotondi, T. Lanzillo, F. Manganelli, F. Lanni, F. Alfano, G. Stanco, G. Rosato.

We report the case of a 67 -year-old female with a wide QRS complex tachycardia at $180 \mathrm{bpm}$.

A diagnosis of class IC atrial flutter with aberrant ventricular conduction caused by flecainide therapy was formulated. Intravenous adenosine administration resulted in adequate slowing of the ventricular rate and normalization
\end{abstract}

of QRS complexes. Restoration of sinus rhythm was achieved with intravenous amiodarone. The response to adenosine confirmed the diagnosis of supraventricular tachycardia with aberrant conduction, but the transition from arrhythmia onset to restoration of sinus rhythm showed interesting peculiarities.

Keywords: adenosine, class IC atrial flutter.

Monaldi Arch Chest Dis 2011; 76: 151-154.

Department of Cardiology and Cardiovascular Surgery, "San Giuseppe Moscati” Hospital, Avellino, Italy.

Corresponding author: Francesco Rotondi, MD; Department of Cardiology and Cardiovascular Surgery, Electrophysiology and Pacing Laboratory, “San Giuseppe Moscati” Hospital; Avellino, Italy; Tel. and Fax+39.0825.203239; E-mail address: francesco.rotondi@tin.it

\section{Introduction}

Class IC antiarrhythmic drugs are known to have the potential to convert atrial fibrillation to atrial flutter, probably by slowing isthmus conduction and/or limiting transverse conduction along the crista terminalis. The incidence of the so-called "class IC atrial flutter" in patients receiving class IC agents for atrial fibrillation is about $3.5-20 \%$ [1].

Slow atrial flutter with 1:1 atrioventricular conduction associated with aberrant ventricular conduction in the setting of class IC antiarrhythmic drug use is not easily distinguishable from ventricular tachycardias. The patient history, the performance of vagal maneuvers and adenosine administration, an antiarrhythmic drug with potent negative dromotropic effects, may often facilitate the diagnosis.

\section{Case Report}

A 67-year-old female was referred to out cardiology department with a well tolerated, sustained, regular, monomorphic wide QRS complex tachycardia at $180 \mathrm{bpm}$ (fig. 1). The patient suffered from hypertension and recurrent persistent atrial fibrillation. She was on flecainide, nebivolol and enalapril.

On admission, her blood pressure was 140/90 $\mathrm{mmHg}$ with an oxygen saturation of $95 \%$.

Laboratory tests were unremarkable, except for elevated glucose $(158 \mathrm{mg} / \mathrm{dl}$; normal range $70-110$ $\mathrm{mg} / \mathrm{dl})$ and urea levels $(47 \mathrm{mg} / \mathrm{dl}$; normal range 15 $45 \mathrm{mg} / \mathrm{dl})$.

Echocardiography showed mild left ventricular hypertrophy, normal systolic function (left ventricu- lar ejection fraction $60 \%$ ), and mild mitral regurgitation.

The clinical picture prompted us to consider the diagnosis of "class IC atrial flutter" with aberrant ventricular conduction caused by flecainide therapy. The patient was given an intravenous bolus of adenosine $(6 \mathrm{mg})$, resulting in adequate slowing of the ventricular rate and normalization of QRS complexes (fig. 2). Restoration of sinus rhythm was achieved with intravenous amiodarone $(0.5 \mathrm{mg} / \mathrm{min})$ (fig. 3).

After two days, the patient was discharged asymptomatic on amiodarone $200 \mathrm{mg}$ twice daily.

\section{Discussion}

The response to adenosine was suggestive of supraventricular tachycardia with aberrant conduction. It is known that adenosine is both useful and safe as a diagnostic agent for the differential diagnosis of wide complex tachycardias [2], but in our case the transition from arrhythmia onset to restoration of sinus rhythm showed interesting peculiarities.

Following adenosine administration, a normalization of the QRS pattern was observed in the absence of any significant decrease in heart rate (fig. 4). It is likely that adenosine induced a slight prolongation of the cardiac cycle length, not detectable at $25 \mathrm{~mm} / \mathrm{sec}$, but sufficient to produce an improvement of the intraventricular conduction and a reduction in QRS duration [3].

Afterwards, the tachycardia tended to be persistent, showing alternating RR-intervals and alternating QRS complexes (fig. 5). The most reasonable 
explanation for this "alternating" tachycardia is that it was due to dual atrioventricular nodal pathways with $2: 1$ block in the fast pathway resulting in alternating conduction along the fast and slow pathways.
The "electrical alternans" was elicited by cycle length alternation of RR intervals [4]. However, the alternating RR-intervals and QRS complexes may be due to decremental conduction through the atrioventricular nodal and His-Purkinje system. Unfortunately, the absence of an electrophysiological study, refused by the patient, can not confirm a dual atrioventricular nodal pathways.

The diagnosis of "class IC atrial flutter" was suspected upon the history of atrial fibrillation treated with flecainide and the ECG findings showing the typical features of aberrant conduction $[5,6]$. Our patient did not meet the conventional diagnostic criteria for ventricular tachycardia, including atrioventric-

Figure 1. - Sustained, regular, monomorphic wide QRS complex tachycardia at $180 \mathrm{bpm}$.
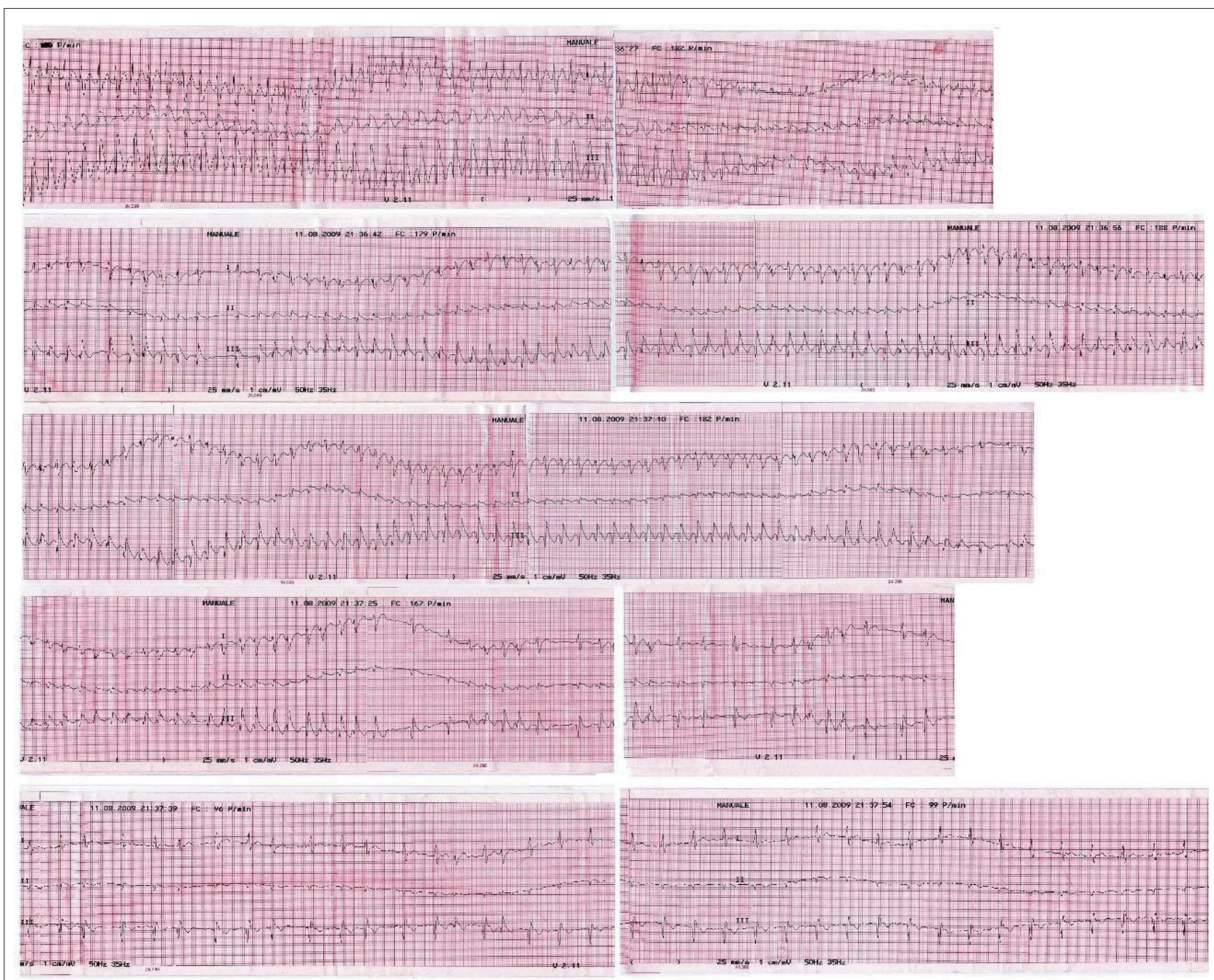

Figure 2. - Adenosine administration resulted in adequate slowing of the ventricular rate and normalization of the QRS complexes. 
ular dissociation, second degree ventriculo-atrial block, capture or fusion beats, concordant precordial pattern, and an interval $>100 \mathrm{~ms}$ from the beginning of the QRS complex to the nadir of the $S$ wave. QRS morphology during ventricular tachycardia showed a pattern of right bundle branch block with $\mathrm{rR}$ ' in V1 and rSr' in V2, which was suggestive of aberrant conduction. The presence of rS complex in V6 is not a sign of ventricular ectopy when there is concomi-

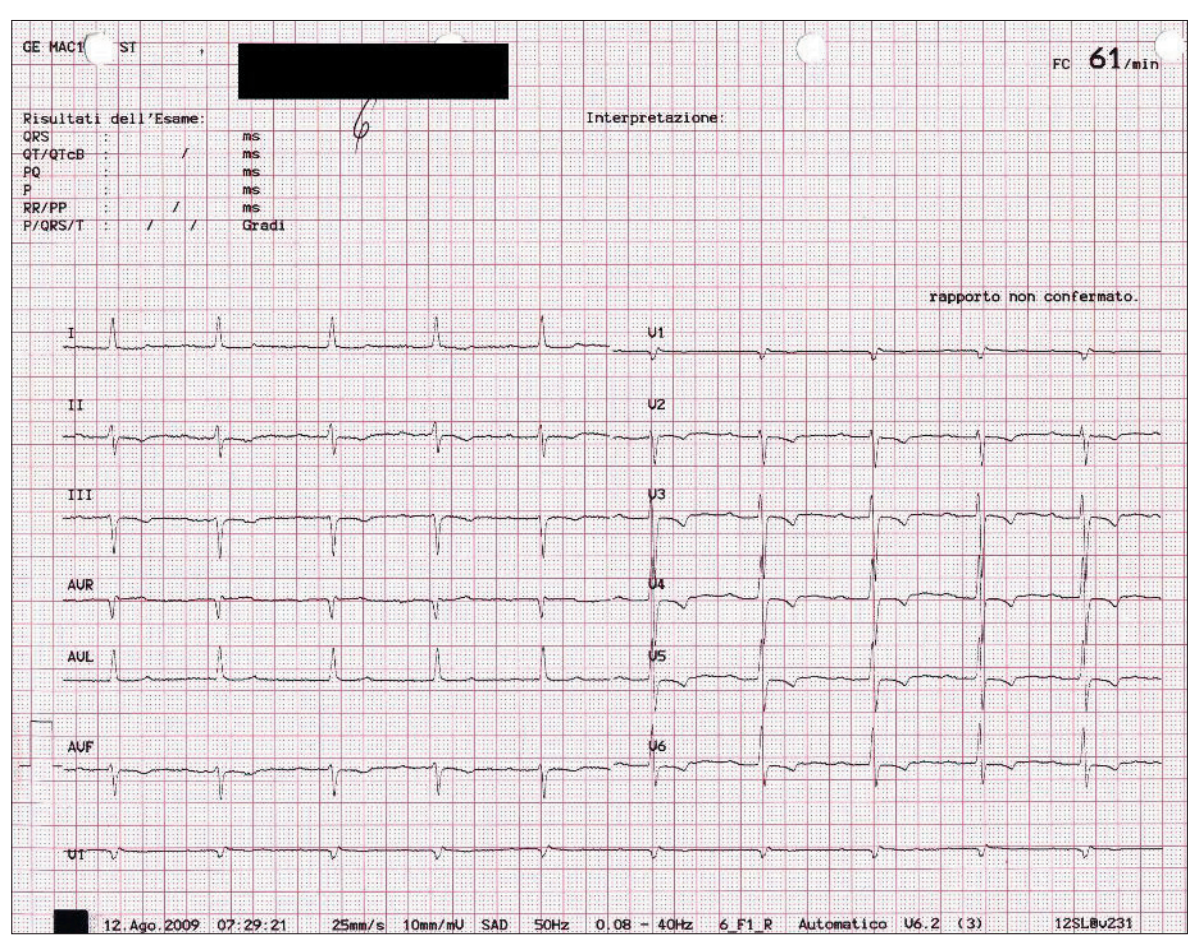

tant extreme QRS axis deviation. A qR pattern in aVR with a $\mathrm{q}$ wave duration $\geq 40 \mathrm{~ms}$ is another typical diagnostic feature of aberrant ventricular conduction [7].

\section{Riassunto}

Riportiamo il caso di una donna di 67 anni con una tachicardia a complessi larghi a 180 bpm. Formulata la diagnosi di "flutter atriale IC" con aberranza di conduzione, causato dall' assunzione di flecainide, veniva somministrata adenosina ev, ottenendo la riduzione della frequenza ventricolare e la normalizzazione dei complessi QRS. Il ripristino del ritmo sinusale si otteneva dopo infusione ev di amiodarone. La risposta all' adenosina confermava la diagnosi $d i$ "flutter atriale IC" ma il passaggio dalla tachicardia iniziale al ritmo sinusale mostrava interessanti peculiarità.

\section{ABBREVIATIONS LIST:}

ECG: electrocardiogram bpm: beats per minute

Figure 3. - Amiodarone administration resulted in restoration of sinus rhythm.

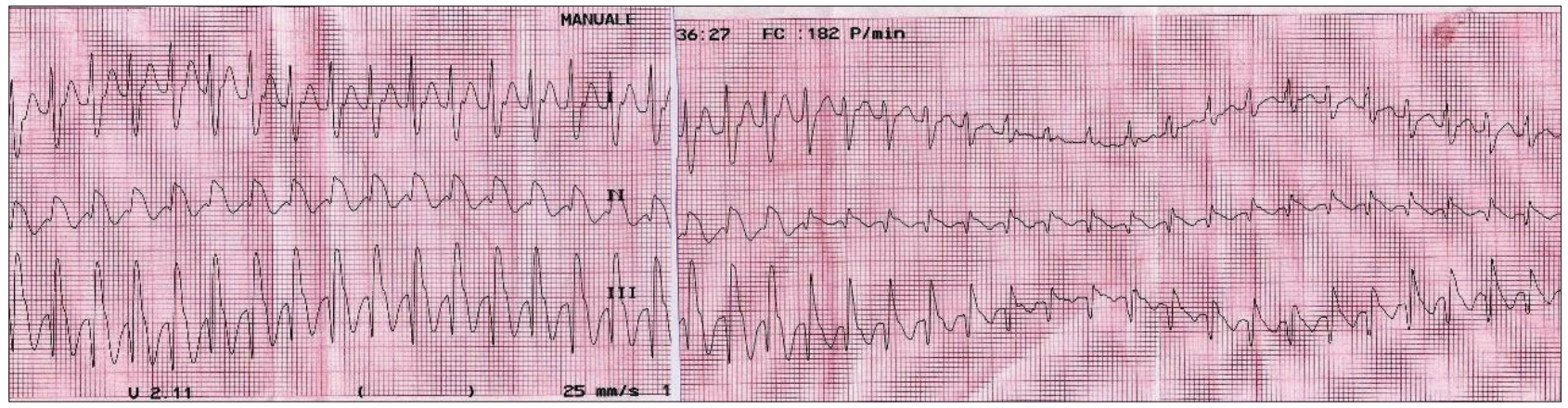

Figure 4. - Following adenosine administration, a transient and unexpected normalization of the QRS pattern was observed in the absence of any significant decrease in heart rate.

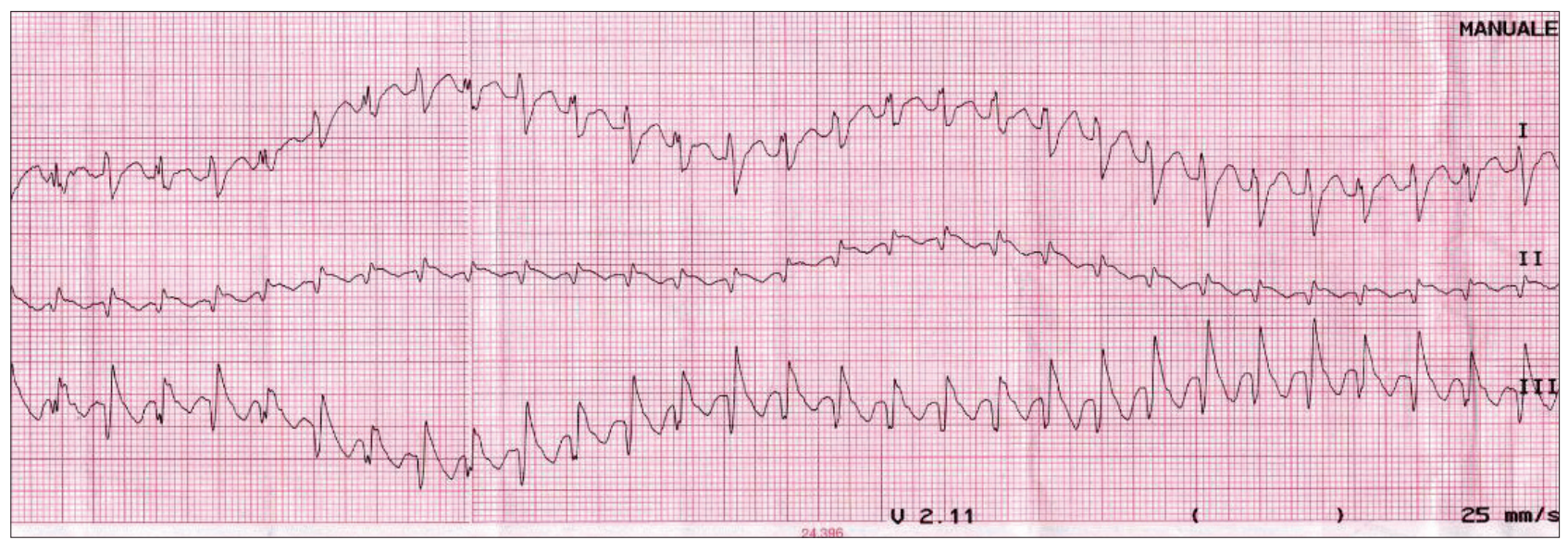

Figure 5. - Persistence of "alternating" tachycardia. 


\section{References}

1. Nabar A, Rodriguez LM, Timmermans C, van Mechelen $\mathrm{R}$, Wellens HJ. Class IC antiarrhythmic drug induced atrial flutter: electrocardiographic and electrophysiological findings and their importance for long term outcome after right atrial isthmus ablation. Heart 2001; 85: 424.

2. Trohman RG. Adenosine for diagnosis of wide QRS tachycardia: rapid infusion for an easier conclusion. Crit Care Med 2009; 37: 2651.

3. Favale S, Di Biase M, Rizzo U, Belardinelli L, Rizzon P. Effect of adenosine and adenosine-5'-triphosphate on atrioventricular conduction in patients. J Am Coll Cardiol 1985; 5: 1212.
4. Brembilla-Perrot B, Lucron H, Schwalm F, Haouzi A. Mechanism of QRS electrical alternans. Heart 1997; 77: 180.

5. Oreto G, Luzza F, Satullo G, Donato A, Carbone V, Calabrò MP. Wide QRS complex tachycardia: an old and new problem. G Ital Cardiol 2009; 10: 580.

6. Brugada P, Brugada J, Mont L, Smeets J, Andries EW. A new approach to the differential diagnosis of a regular tachycardia with a wide QRS complex. Circulation 1991; 83: 1649.

7. Vereckei A, Duray G, Szenasi G, Altemose GT, Miller JM. New algorithm using only lead aVR for differential diagnosis of wide QRS complex tachycardia. Heart Rhythm 2008; 5: 89. 